To the paper

\title{
ERRATA
}

\section{PLUTONIUM CONCENTRATION DISTRIBUTION IN BED LOAD SEDIMENT SAMPLES ALONG THE ROMANIAN SECTOR OF THE DANUBE RIVER AND THE BLACK SEA COAST}

Silvia-Angela Mihai, G. Shaw,* Iulia I. Georgescu

"Politehnica" University, Faculty of Industrial Chemistry, Calea Grivitei 132, Bucharest 78122, Romania

*Centre for Analytical Research in the Environment, Silwood Park, Ascot, Berkshire SL5 7TE, UK

appeared in the Journal of Radioanalytical and Nuclear Chemistry, Letters 212 (1996) No. 6, 461-469.

On page 467 , Table 2, Column 3 should read " $\mathrm{Pu}, \mathrm{mBq} / \mathrm{kg}$ dry" instead of " $239 \mathrm{Pu}, \mathrm{mBq} / \mathrm{kg}$, day".

On pages 462-469 the header should read "PLUTONIUM CONCENTRATION DISTRIBUTION" instead of "THE POLONIUM DISTRIBUTION".

To the paper

\section{POLONIUM CONCENTRATION DISTRIBUTION IN BED LOAD SEDIMENT SAMPLES ALONG THE ROMANIAN SECTOR OF THE DANUBE RIVER AND THE BLACK SEA COAST}

Silvia-Angela Mihai, G. Shaw,* Iulia I. Georgescu

"Politehnica" University, Faculty of Industrial Chemistry, Calea Grivitei 132, Bucharest 78122, Romania

*Centre for Analytical Research in the Environment, Silwood Park, Ascot, Berkshire SL5 7TE, UK

appeared in the Journal of Radioanalytical and Nuclear Chemistry, Letters 213 (1996) No. 1, 1-8.

On page 6, the first sentence of RESULTS AND DISCUSSION should read "the concentration of $210 \mathrm{Po}$ in the investigated..." instead of "The concentrations of ${ }^{208}$ Po and ${ }^{210}$ Po in the investigated..."

To the paper

\section{QUANTITATIVE DETERMINATION OF CHELATORS AND THEIR DEGRADATION PRODUCTS \\ IN MIXED HAZARDOUS WASTES FROM TANK 241-SY-101 USING DERIVATIZATION GC/MS}

K. E. GRANT*, G. M. MONG, R. B. LUCKE, J. A. CAMPBELL**

Advanced Organic Analytical Methods Development Group, Pacific Northwest National Laboratory, Box 999, Richland, WA 99352, USA

appeared in the Journal of Radioanalytical and Nuclear Chemistry, Articles 211 (1996) No. 2, 383-402.

According to the request of the authors, the last paragraph on page 399 and the first paragraph on page 400 should be replaced by the followings:

"The observed yield for HEDTA was 30\%. The sensitivity or response factor of methylated-HEDTA was substantially lower than that of EDTA or NTA, 70\% less on a molar basis. This phenomenon was also observed by TOSTE et al. ${ }^{18}$

To determine whether the trimethylated HEDTA was possibly sorbed onto the GC column, TOSTE et al. ${ }^{18}$ performed two experiments. First, HEDTA was silylated and the product was analyzed. As a second test, methylated-HEDTA was silylated using the silylating reagents $\mathrm{N}$-bis(trimethylsilyl)acetamine (BSA) and trimethylchlorosilane (TMCS). The results confirmed that the underivatized hydroxyethyl group of HEDTA was to polar to pass through the GC column. When analyzing chelating agents or their degradation products, similar chemical complexities are often encountered." 